\title{
Study on the Training of Innovative Talents of Electrical Information Majors by Science \& Technology Competition and Innovation \&Entrepreneurship Training Programs
}

\author{
Yansheng Zhang \\ School of Electrical Engineering \& Information \\ Northeast Petroleum University \\ Daqing, China \\ lencyice@163.com
}

\author{
Keyong Shao \\ School of Electrical Engineering \& Information \\ Northeast Petroleum University \\ Daqing, China \\ 1783811235@qq.com
}

\begin{abstract}
Science and technology competition and innovation and entrepreneurship training programs are important methods to promote the students engaged in scientific and technological innovation activities and to train students' innovative ability of science and technology. Several measures are taken to systematically carry out science and technology competition and innovation and entrepreneurship training program for the majors of electrical information. And a training system is developed for the innovative talents of electrical information major.
\end{abstract}

Keywords-science and technology competition; innovation \& entrepreneurship training program; innovative talents

\section{INTRODUCTION}

With the development of higher education and the progress of the society, the cultivation of innovative talents has become one of the major tasks of the University. Science and technology competition for undergraduates and national undergraduate innovation \& entrepreneurship training programs (which were abbreviated as STC and IETP) break the previous teaching mode which pay too much emphasis on theoretical knowledge and ignore the cultivation of students' creative ability. Because they emphasize that both teachers and students participate the design and the development of the works of the science and technology competition. They have become the main means and breakthrough for colleges and universities to cultivate the innovation spirit and the practice ability of the undergraduates How to encourage students to actively participate in STC and IETP, how to build a scientific, standardized, systematic management mechanism to establish the platform of training innovation ability of college students, are the subjects worthy of exploration and research for colleges and universities at present.

Science and engineering talents training focus on training the comprehensive ability and innovation ability. Along with the social increasing demand for practical talents, it is necessary for colleges and universities to break the traditional practice teaching and management mode which lead to difficult obtain employment for graduates. And it is necessary to cultivate undergraduates' ability of creative learning and using the method of creative thinking to have courage to invention and innovation. STC and IETP are the important means to promote the students engaged in scientific and technological innovation activities and the main method to cultivate undergraduates' innovative ability of science and technology. They are also important construction contents of the education reform project 'quality project'. So, improving the practice teaching system of applied talents, exploring the new ability training mode, building the graduates' science and technology innovation platform, have the extremely vital significance to the cultivation of innovative talents of electrical information.

\section{CORE CONCEPTS}

\section{A. Innovative Talents}

Innovative talents are the people who are full of pioneering spirit, have the ability to create, can open up a new situation and make a creative contribution to the social development [1]. They usually exhibit flexible, open and curious personality. Their characteristics are full of go, persevere unremittingly, concentrate attention, are imaginative and adventurous, and so on. The innovative talents have the following special characteristics: (1) strong curiosity and desire for knowledge;

(2) Strong self learning and exploring ability; (3) broad and solid knowledge in a particular area or a area and higher professional level ; (4) good moral self-cultivation to cooperate with others; (5) healthy body and good psychological quality to bear the burden of hard work. In a word, innovative talents should have the three basic elements of personality, intelligence and psychology.

\section{B. Science and Technology Competition}

Science and technology competitions include various contests which are held out of classroom teaching and have close relationship with the curriculum in colleges and universities. Science and technology competitions need integrate several course knowledge to solve practical problems or specific design problems [2]. The national competitions that the undergraduates take part in for electrical information 
include: Mathematical Contest in Modeling, "Challenge Cup" National Undergraduate Extracurricular Scientific Work Competition, " Freescale Cup " National Smart Car University Design Competition, National Undergraduate Electronic Design Contest, "MEMSIC Cup" MEMS sensor application contest in china, "Siemens cup" national undergraduate control and simulation challenge

\section{Undergraduate Innovation \& Entrepreneurship Training Program}

National undergraduate innovation \& entrepreneurship training program is that the undergraduates or the creative teams are based on the specialty and the interest of the undergraduate to implement the innovation \& entrepreneurship project under the instruction of the teacher. The undergraduates or the creative teams can select the subject independently and research the project independently including processing the information and writing summary reports etc. Innovation \& entrepreneurship training program emphasizes on process training and independent design to stimulate students' interest in scientific research and it can cultivate students' abilities of autonomous learning, team cooperation and putting forward problem, analyzing problem and solving problem [3].

\section{IMPLEMENT OF THE SCIENCE AND TECHNOLOGY COMPETITION AND INNOVATION \& ENTREPRENEURSHIP TRAINING PROGRAM}

The purposes of STC and IETP are to cultivate students' practical ability, innovation ability and research ability, guide the students to pay attention to the world, understand the livelihood of the people, and integrate into society through their own experience. STC and IETP can be divided into three stages: the first is the preparation stage. The undergraduates can accumulate theory knowledge, practical abilities and mental qualities in this stage to determine the subjects. The second is implementation process. The undergraduates use the theory knowledge and practical abilities to analyze the problems, formulate schemes and solve the problems in this stage. The third is the closing stage. In this stage the undergraduates reflect, review and summarize the competition or the project.

The relationship between the cultivation of students innovative ability and STC \& IETPthe science and technology competition and innovation \& entrepreneurship training program is shown in FIGURE I.

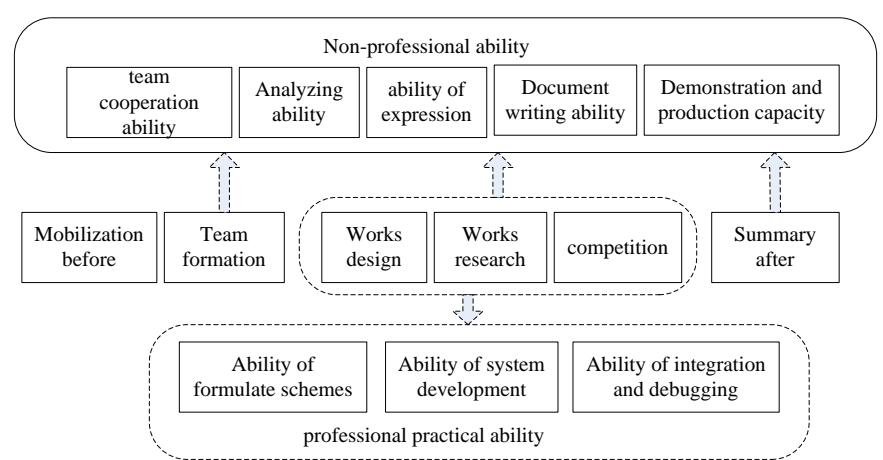

FIGURE I THE RELATIONSHIP BETWEEN THE CULTIVATION OF STUDENTS' INNOVATIVE ABILITY AND STC \& IETP

\section{A. Building A Culture of Innovation in Science and Technology Education for Students}

To cultivate innovative talents, the university should take the whole situation into account and plan accordingly, developing the science and technology culture sustainable environment. If the technological innovation culture is present in the students and teachers' ideas, which is the carrier of students' innovative ability and means to develop the scientific and technological innovation culture as an invisible spirit of philosophy, it will effect on the formation of the students' technological innovation idea, the students' technological innovation ability and the students' technological innovation quality, and will finally improve the development of the scientific competition and innovative experiment by way of cognizing, orienting, edifying, encouraging, regulating, demonstrating and assimilating.

\section{B. Carrying Out Various Scientific and Technological Contests to Develop the Innovation Ability of Students}

Technology competition is that several students as a team accomplish a piece of technology work or design in a limited time and tense atmosphere. Team members discuss the competition subject based on their members' knowledge, and then divide the teamwork tacitly: race director, data collection and analysis, computer operations, thesis writing, different solutions development, revision and selection, production and commissioning works, various types of work assistants, and the roles of members have been changed constantly during the contest.

\section{Encouraging Students to Declare All Levels of Innovation and Entrepreneurship Training Projects to Develop Their Scientific and Technological Innovation Capabilities}

Undergraduate Training Programs for Innovation and Entrepreneurship is one of the projects of the Ministry of Education's quality engineering projects. In the innovative experiment, students do the fundamental practice under the guidance of teachers during one year-long study, the students have to collect information, carry experimental operation, but also study the relevant professional knowledge by themselves. This also increases the time that students interact with teachers. This student-centered practice teaching mode allows students to experience the full academic atmosphere in the process of scientific research, to get the training of scientific research methods, to develop the habit of active learning and to hone the student's personal qualities.

\section{Providing Academic Seminars and Workshops}

Various forms of lectures and workshops carried out on competitions and innovation and entrepreneurship training will complement the students' knowledge and technology, develop the students' scope of knowledge, and promote the transformation of theoretical knowledge into design techniques and skills. On the other hand, winning student's personal competition experience and feelings has also inspired other students to engage in science and technology competitions.

\section{E. Promoting the Construction of Related Courses}

Technology and innovation contest activities and entrepreneurship training projects are the integrated use and 
extension of curricular knowledge, so we should pay attention to construction of practical courses, such as basic training, comprehensive training and professional training. And elective courses of science of creation, and innovative thinking and other contest-related coursed should be provides, so that students can improve operational capability and professional research ability during curricular and teaching practices.

\section{THE INITIAL FORMATION OF CHARACTERISTICS FOR} CULTIVATE INNOVATIVE TALENTS OF ELECTRIC INFORMATION

\section{A. Supporting the Development of Students' Scientific and Technological Associations}

The Students' Associations are also good carriers for technological innovation activities. The Students' Associations can attract students to various scientific and technological innovation activities by participating in science and technology competitions, reporting innovative experimental projects, science and technology festivals organized by students, all kinds of academic lectures, science and technology salons, and exhibitions of college extracurricular academic and technological achievements. Through these extracurricular practice activities, the students' pragmatic spirit and team spirit are developed, and the scientific and technological innovation literacy of the association members are increased.

\section{B. Establishment of Innovative Experimental Class}

High-performance students and students talented in curtained fields are selected and mixed in innovative experimental class to perform elite education and practical education. In the innovative experimental classes, science and technology competitions and innovation experiments are the efficient carriers of practical teaching activities. Students' ability to acquire knowledge, the ability to apply theoretical knowledge to solve practical problems, and the capability of technological innovation are developed through a variety of practical trainings including science and technology competitions and innovative experimental projects. The group practice in innovative practice class can also create a strong atmosphere of technological innovation competition, and stimulate the students' enthusiasm for innovation

\section{Making STC and IETP A Useful Supplement to the \\ Teachers' Research}

Because of the imperfect knowledge structure, and the relative lacking of experience in science and technology competition of the students, it is difficult to choose project topics for innovation and entrepreneurship in science and technology competitions and training. The students' technology competition and innovation and entrepreneurship training programs are combined tightly with the research of the faculty. It is mainly reflected in two aspects. On one hand, parts of the teachers' research are transformed into project topics of student technology competition and innovation and entrepreneurship training. On the other hand, teachers are encouraged to include students into their research groups, and to take the mature innovative ideas and research results of the students, to further promote the students' work via joint research with the students. The guidance of teachers, the necessary funding and equipment are necessary for the students to perform profound scientific research, so that their ability to innovate can be further improved.

\section{CONCLUSIONS}

In summary, cultivating innovative talents is the needs of society development, and is also the current primary task of the higher education. It is an urgent question we need to think deeply during practical teaching that how to let the students learn new techniques with the rapid development of science and technology, how to develop their innovation enthusiasm and capability, and how to improve their overall quality. STC \& IETP offer a great opportunity for deepening the course content reformation and developing students' practical ability. After several years of exploration, innovation and research, the automation science major of our college finds out that the integration of the technology innovation and entrepreneurship competitions and training programs into teaching work, is an effective way to develop the students' creative thinking, innovation capability, teamwork, problem solving and practice abilities.

\section{ACKNOWLEDGMENT}

This research was financially supported by the Key Topic of Heilongjiang Province of China (Grant NO.GBB1212018)

\section{REFERENCES}

[1] Zhang Feng, Li Tao. Cultivating Innovative Talents by Science and Technology Competition[J]. Education Teaching Forum. 2010(15)

[2] Zhang Shuqin, Dong Yuejun, Dong Zhiyong. Training of Innovation and Practice Abilities for Computer Science Specialty by Scientific Works Contests. Computer Education.2010(17)

[3] Ren Liangyu, Zhang Jiwei. Institutional and Cultural Environment for Innovative Undergraduate Education — the Case of "National Undergraduate Innovation Experiment Project"[J]. Research on Education Tsinghua University 